\title{
The effects of changing solar activity on climate: contributions from palaeoclimatological studies
}

\author{
Stefan Engels ${ }^{1, *}$ and Bas van Geel ${ }^{1}$ \\ 1 Institute for Biodiversity and Ecosystem Dynamics, University of Amsterdam, Science Park 904, P.O. Box 94248, \\ NL-1090 GE Amsterdam, The Netherlands \\ *corresponding author: e-mail: s.engels@uva.nl
}

Received 6 March 2012 / Accepted 9 July 2012

\begin{abstract}
Natural climate change currently acts in concert with human-induced changes in the climate system. To disentangle the natural variability in the climate system and the human-induced effects on the global climate, a critical analysis of climate change in the past may offer a better understanding of the processes that drive the global climate system. In this review paper, we present palaeoclimatological evidence for the past influence of solar variability on Earth's climate, highlighting the effects of solar forcing on a range of timescales. On a decadal timescale, instrumental measurements as well as historical records show the effects of the 11 -year Schwabe cycle on climate. The variation in total solar irradiance that is associated with a Schwabe cycle is only $\sim 1 \mathrm{~W} \mathrm{~m} \mathrm{~m}^{-2}$ between a solar minimum and a maximum, but winter and spring temperatures on the Northern Hemisphere show a response even to this small-scale variability. There is a large body of evidence from palaeoclimatic reconstructions that shows the influence of solar activity on a centennial to millennial timescale. We highlight a period of low solar activity starting at 2800 years before present when Europe experienced a shift to colder and wetter climate conditions. The spatial pattern of climate change that can be recognized in the palaeoclimatological data is in line with the suggested pattern of climate change as simulated by climate models. Millennial-scale climate oscillations can be recognized in sediment records from the Atlantic Ocean as well as in records of lake-level fluctuations in southeastern France. These oscillations coincide with variation in ${ }^{14} \mathrm{C}$ production as recognized in the atmospheric ${ }^{14} \mathrm{C}$ record (which is a proxy-record for solar activity), suggesting that Earth's climate is sensitive to changes in solar activity on a millennial timescale as well.
\end{abstract}

Key words. solar activity - sunspot - paleoclimatology - proxies

\section{Introduction}

Predictions of future climate change that can result from a human-induced increase in atmospheric carbon dioxide and methane levels are alarming (IPCC 2007). Natural climate change is currently acting in concert with human-induced changes in the climate system and it is important to separate the effects of different forcing agents in order to determine to what extent the late 20th-century changes may be unusual in the light of preindustrial natural climate variability (Luterbacher et al. 2004). The idea of solar forcing of Earth's climate dates back to the early 19th century (Herschel 1801; Gray et al. 2010), but the role of solar variability as a forcing mechanism is still poorly understood.

To disentangle the natural variability in the climate system and the human-induced effects on the global climate, a critical analysis of climate change in the past may offer a better understanding of the processes acting on the Earth's surface and driving the global climate system. Recent periods of low solar variability such as the Maunder Minimum (Eddy 1976) and its effects on climate (the Maunder Minimum was part of the so-called Little Ice Age) have indeed been documented in historical records. However, the period for which there are historical records of changes in, for instance, precipitation or temperature is (in geological terms) relatively short. In most regions instrumental records do not start earlier than the 19th century. In order to reconstruct processes driving climate change on a longer timescale, we have to use indirect measurements of relevant parameters of the climate system, viz. proxyindicators for climate change and for changing solar activity.

A wide range of proxies and techniques are available to study past changes in the climate system, and sediments, peat deposits, accumulated ice and even tree rings provide natural archives in which these proxies are preserved. These natural archives are available on large parts of the globe, covering the continents, the oceans and the ice caps of Greenland and Antarctica. This offers the potential to reconstruct spatial patterns in past climate change. The knowledge of both pattern and timing of climate change in the past is a prerequisite in order to understand the causes of changing climate at various timescales (Vandenberghe et al. 1998). In this review, we discuss different natural forcing mechanisms that affect climate at the Earth's surface as well as some of the hypotheses that are proposed to explain amplification of the relatively small variability in total solar irradiance to large-scale processes that can influence the climate system. We then review palaeoclimatological evidence for past influence of solar variability on the climate, showing the effects of changing solar forcing on a range of timescales. We conclude this review with some remarks on the potential of climate model simulations. 


\section{Forcing factors}

\subsection{Orbital forcing}

The amount of solar radiation that reaches the top of the atmosphere depends on the position of the Earth in relation to the Sun as well as on the activity of the Sun itself. The effect of the poly-cyclic behavior in the Earth's position relative to the sun on Earth's climate was first described by Milankovitch (1941). The effects of the Milankovitch cycles on Earth's climate are well known as orbital forcing. Variations in eccentricity (departure from a circular orbit, varying with a 100 and $400 \mathrm{kyr}$ periodicity), obliquity (axial tilt, varying with a $41 \mathrm{kyr}$ period) and precession (rotation of the Earth's axis, varying with a 19-23 kyr periodicity) of the Earth's orbit determine major climatic changes on Earth (e.g. Berger 1988). On a Quaternary timescale (i.e. the last $2.6 \mathrm{Myr}$ ), the combined effects of changing eccentricity, obliquity and precession have resulted in a dynamic climate that is characterized by variations between long glacial periods and relatively short interglacials. The onset of the current interglacial, the Holocene, occurred during an increase in solar insolation received by the upper atmosphere. Northern hemispheric summer insolation has shown a steady decline during the past $11 \mathrm{kyr}$, resulting in gradually declining temperatures over large parts of the Northern hemisphere (e.g. Renssen et al. 2009). Variation in orbital forcing is a large-scale, gradual mechanism which is superimposed by shorter variations in other forcing factors such as solar and volcanic forcing.

\subsection{Solar forcing}

Changes in total solar irradiance (TSI) result from cyclic changes in the Sun's magnetic activity and are superimposed on (long-scale) changes caused by orbital forcing. Instrumental data that span the past three decades clearly show the cyclic signal of changes in TSI with a periodicity of $\sim 11$ years (Schwabe cycle) between a sunspot minimum and a sunspot maximum. The measured difference between a minimum and a maximum is approximately $1 \mathrm{~W} \mathrm{~m}^{-2}$ (Fröhlich 2006). Taking into account the albedo and the shape of the Earth, this results in a variation of energy available to the Earth (radiative forcing) of $\sim 0.17 \mathrm{~W} \mathrm{~m}^{-2}$, which is a small number compared to the estimated radiative forcing by trace greenhouse gasses of $2.45 \mathrm{~W} \mathrm{~m}^{-2}$ (Lockwood 2012).

The instrumental observations of TSI variability can be complemented by historical observations of solar activity. For instance, the observations of sunspots go back to $1610 \mathrm{AD}$ and a combination of the 11-year Schwabe cycle with longer cyclic patterns in solar activity (e.g. the Gleissberg cycle of $\sim 80-90$ years) can be observed in the historic records. The combined effect of these cycles resulted in prolonged periods of low solar activity such as the Maunder Minimum at 16451715 AD and the Dalton Minimum at 1795-1820 AD. These periods of low solar activity coincided with colder climate conditions over parts of the northern Hemisphere, also known as the Little Ice Age.

Longer records of changes in solar activity can be reconstructed from cosmogenic isotope records as stored in ice cores (Steinhilber et al. 2009) and tree rings (Stuiver et al. 1998; Reimer et al. 2009). Beryllium-10 is a cosmogenic radionuclide that is produced in the upper atmosphere as a result of the interaction of galactic cosmic rays with nitrogen and oxygen (e.g. McHargue \& Damon 1991). During periods of high solar activity (strong "solar wind") the intensity of cosmic rays that can reach Earth's upper atmosphere is lower and the amount of ${ }^{10} \mathrm{Be}$ that is produced is lower. Vice versa, with low solar activity more ${ }^{10} \mathrm{Be}$ is produced in the upper atmosphere (Steinhilber et al. 2009). As ${ }^{10} \mathrm{Be}$ attaches to aerosols it is removed from the atmosphere and deposited on Earth's surface within 1-2 years (Beer \& van Geel 2008). A record of past TSI can be reconstructed from measurement of the ${ }^{10} \mathrm{Be}$ content of ice cores, a natural archive that can be analysed with a high resolution (up to annual data). Steinhilber et al. (2009) determined the relationship between TSI and ${ }^{10} \mathrm{Be}$ production and applied this relationship to measurements of ${ }^{10} \mathrm{Be}$ in ice cores in order to reconstruct changes in TSI over the past 9300 years. Their results indicate that periods with low solar activity such as the Maunder Minimum had a TSI that was $0.9 \pm 0.4 \mathrm{~W} \mathrm{~m}^{-2}$ lower compared to the present. Reconstructed variations in TSI for periods further back in time were even higher, with a particularly large estimated decrease in TSI of $\sim 1.7 \mathrm{~W} \mathrm{~m}^{-2}$ at 2800 years before present (BP). Simultaneous with storing information on past variations in TSI, ice cores archive information on environmental response (e.g. ${ }^{16} \mathrm{O} /{ }^{18} \mathrm{O}$ ratios; Johnsen et al. 1992) to changing climatic conditions.

Radiocarbon $\left({ }^{14} \mathrm{C}\right)$ is a cosmogenic isotope that forms in the atmosphere from the reaction between neutrons (generated by colliding cosmic rays) and nitrogen. A reduction in solar activity will lead to an increase in the cosmic ray flux, leading to an increase in ${ }^{14} \mathrm{C}$ production. After formation, ${ }^{14} \mathrm{C}$ bonds to $\mathrm{O}_{2}$ forming ${ }^{14} \mathrm{CO}_{2}$ that exchanges between atmosphere, ocean and biosphere. ${ }^{14} \mathrm{C}$ is a radioactive isotope and as its half-life is 5730 years, measurements of the ${ }^{14} \mathrm{C}$ content of fossil organic material have enabled the dating of many palaeoclimatological archives with a maximum age of ca. 50,000 years BP.

The production of ${ }^{14} \mathrm{C}$ depends on the amount of cosmic rays that reach the upper atmosphere, which has not been constant over the past but which has been modulated by changes in the strength of the solar wind. A record of past atmospheric ${ }^{14} \mathrm{C}$ levels (the so-called calibration curve and the subsequently derived $\Delta^{14} \mathrm{C}$ signal) of the past $\sim 11,000$ years has been derived from radiocarbon dates of dendrochronologically dated wood (e.g. Stuiver \& van der Plicht 1998; Reimer et al. 2009). Wiggles in the calibration curve indicate variations in past solar activity, which can be compared to geological evidence for past climate change (e.g. Bond et al. 2001; Magny 2006).

\subsection{Other forcing mechanisms}

Three natural forcing factors influenced global climate during most of the Holocene: orbital forcing, solar forcing and volcanic forcing (e.g. Wanner et al. 2008). These three forcing factors interplay with changes in other forcing factors such as changes in land cover, concentrations of greenhouse gasses, albedo- and stratospheric ozone levels, resulting in a complex system of forcings and feedbacks. Below we discuss several of these potential forcing and feedback mechanisms (both positive and negative).

Large amounts of tephra and gasses are emitted into the atmosphere during large volcanic eruptions. Especially the acids that form from the released sulphur gasses remain in the atmosphere for an extended time and these cause absorption of solar radiation and cooling at the Earth's surface (Wanner et al. 2008). This forcing is mainly effective during the summer months on the Northern Hemisphere, when radiation dominates the temperatures at the Earth's surface. In winter, a positive North Atlantic Oscillation (NAO)-index (e.g. Hurrell \& van Loon 1997) and increased strength of the prevailing westerlies will result in a 
slight warming of the continents on the Northern Hemisphere (Graf et al. 1993). Robock (2000) estimates that the net cooling effect of the six largest eruptions of the past century has been $0.1-0.2{ }^{\circ} \mathrm{C}$ (annual surface air temperature).

The role of greenhouse gasses such as $\mathrm{CO}_{2}, \mathrm{CH}_{4}$ and $\mathrm{N}_{2} \mathrm{O}$ in the climate system has been amply discussed. An increase in the atmospheric concentration of these gasses will lead to an increased re-radiation of thermal radiation from the Earth's surface and therefore in warming at the surface. All three before-mentioned greenhouse gasses show a steady increase in concentrations during the middle and late Holocene. This increase in $\mathrm{CO}_{2}$ concentrations might have been the result of a progressive release of carbon by the terrestrial biosphere (Indermühle et al. 1999) or alternatively it might have resulted from a change in the ocean's carbon balance (Broecker 2001). Even anthropogenic influence as early as the middle Holocene has been suggested as an explanation of the rise in atmospheric $\mathrm{CO}_{2}$ levels (Ruddiman 2003). The preindustrial increase in greenhouse gasses in the atmosphere probably only resulted in a net change in temperature at the Earth's surface of $0.3{ }^{\circ} \mathrm{C}$ (Wanner et al. 2008). Only after $\sim 1750 \mathrm{AD}$ do the greenhouse gasses show a sharp increase in both rate and magnitude of change (Joos \& Spahni 2008).

Changes in land cover can result in changes in the atmosphere through changes in albedo as well as in surface roughness. For instance, deforestation of large areas of land in Europe could have resulted in regional cooling due to albedoand latent heat feedbacks (Diffenbaugh \& Sloan 2002). Similarly, drainage of peatlands might have promoted the release of $\mathrm{CO}_{2}$ and $\mathrm{CH}_{4}$ into the atmosphere, starting a positive feedback mechanism. Sea-ice cover forms another strong positive feedback mechanism. Warming will result in a decrease in the extent of sea-ice, which results in a decrease in albedo and therefore in an increase of energy uptake by the ocean. This feedback mechanism is responsible for the amplification of climate change in high-latitudinal regions.

\section{TSI and climate: direct influence and feedback mechanisms}

A cyclicity with an 11-year period has been observed in instrumental records of TSI measurements over the past 3 decades (Fröhlich 2009). The measured difference of energy received at the top of the atmosphere is $\sim 1 \mathrm{~W} \mathrm{~m}^{-2}$ between a solar minimum and a solar maximum. This results in a change in radiative forcing of $0.17 \mathrm{~W} \mathrm{~m}^{-2}$ at the Earth's surface, which is much smaller than the $3.7 \mathrm{~W} \mathrm{~m}^{-2}$ change that is estimated to result from a doubling in atmospheric $\mathrm{CO}_{2}$ levels (IPCC 2007). Nevertheless, historic as well as palaeoclimatic records indicate that variations in TSI did significantly influence Earth's climate (see Sect. 4). Several feedback or amplification mechanisms have been proposed in order to explain how the relatively small changes in TSI could influence Earth's climate system.

\subsection{Direct influence of TSI}

A primary effect of solar variability on climate is the direct influence on the energy balance of the Earth. The average estimated global temperature change directly resulting from the difference between a 20th-century 11-year maximum and a minimum is $\sim 0.07{ }^{\circ} \mathrm{C}$ (Gray et al. 2010). However, the changes in temperature at the surface are spatially diverse and regional changes in temperature can be much higher than the mere average of $0.07{ }^{\circ} \mathrm{C}$ (Gray et al. 2010).

The direct effects of TSI on climate are amplified by a mechanism that is often referred to as the "bottom-up mechanism", which mainly involves the uptake of solar heat by the ocean. The bottom-up mechanism involves increasing solar absorption over relatively cloud-free subtropical oceans during solar maxima (Cubasch et al. 1997, 2006; Gray et al. 2010). An increase in solar absorption leads to an increase in evaporation, which will result in an increase in the amount of moisture that converges in the precipitation zones, leading to higher precipitation maxima. The intensified precipitation maxima and the associated upward vertical motions result in stronger trade winds, greater equatorial Pacific ocean upwelling and colder SSTs consistent with stronger Hadley circulation (Meehl et al. 2004; Gray et al. 2010). A strengthened atmospheric circulation enhances subtropical subsidence, resulting in a positive feedback mechanism of a further reduction in cloud formation and an increased solar absorption at the surface (e.g. Meehl et al. 2008, 2009; Gray et al. 2010).

\subsection{Response to variation in UV irradiance}

Variability in TSI is strongly wavelength dependent, where large changes are seen in the UV part of the spectrum (Gray et al. 2010). An increase in solar UV intensity leads to an increase in stratospheric ozone production. Ozone is an important agent in the radiative heating in the stratosphere (Gray et al. 2010) and an increase in ozone production will lead to changes in stratospheric winds and an increase in absorbed solar energy and thus heating of the stratosphere (e.g. Haigh 1996). There is growing evidence that dynamical coupling across the tropopause means that changing stratospheric temperatures and winds can influence the underlying troposphere (Matthes et al. 2006; Gray et al. 2010; Lockwood et al. 2010). For instance, disturbances of the stratospheric polar vortex could affect the tropospheric jets (Baldwin \& Dunkerton 1999). Alternatively, solar-induced stratospheric changes may influence the refraction of tropospheric eddies (e.g. Kushner \& Polvani 2004; Simpson et al. 2009). Although the mechanisms behind the coupling of the stratosphere and the troposphere are not yet fully understood, it seems likely that UV heating of the stratosphere indirectly influences the troposphere (Gray et al. 2010; Lockwood et al. 2010). The effect of changes in TSI on processes in the stratosphere, ultimately leading to changes in tropospheric climate, is often referred to as the "top-down mechanism".

Observations show that the 11-year variation in TSI indeed results in a $\sim 2 \mathrm{~K}$ response of temperatures in the upper tropical stratosphere (Frame \& Gray 2010). Gray et al. (2009) estimate that half of this signal is caused by direct effects of changes in solar irradiance and that the other half results from the topdown mechanism (Gray et al. 2010). Simulations with an atmospheric model showed that a $1 \%$ increase in UV radiation at the maximum of a solar cycle generated a $1 \%-2 \%$ increase in ozone concentrations in the stratosphere. Haigh (1996) modeled the effects of an increase in ozone in the stratosphere and showed that a broadening of the latitudinal extent of the Hadley cell circulation occurred together with a poleward relocation of mid-latitudinal storm tracks. This would lead to warming in the mid-latitudes, regional decreases in precipitation and wetter conditions in the tropics. Section 4.2 discusses palaeoclimatic evidence that supports the model outcome by Haigh (1996). 


\subsection{Cosmic ray-induced changes in cloud cover}

An alternative link between solar activity and climate change is the hypothesis that cosmic rays can aid the formation of clouds. Clouds can have a significant effect on Earth's climate as they (1) change the albedo of the Earth and (2) enhance the greenhouse trapping effect (Lockwood 2012). Svensmark \& Friis-Christensen (1997) published a controversial paper that investigated the influence of cosmic ray flux and cloud formation and concluded that there is a strong correlation between solar activity and cloud cover. According to Svensmark et al. (2009), clouds in the lower atmosphere (below $3 \mathrm{~km}$ altitude) contain less liquid water during times of low cosmic ray fluxes. Furthermore, the relative abundance of aerosols (which could potentially evolve into cloud condensation nuclei) decreases during such periods, providing for a causal mechanism between solar activity and cloud formation. Svensmark \& Friis-Christensen (1997) state that total cloud cover exerts a net negative radiative forcing of the climate system, because the reflection of solar radiation due to increased cloudiness is stronger than the cloud-enhanced greenhouse effect in the IR part of the spectrum.

Critical responses to the initial publication of Svensmark \& Friis-Christensen (1997) stated that these authors did not take the optical thickness of the clouds into account (Jørgensen \& Hansen 2000), or that their calculation of the radiative effects of increased cloudiness is flawed (Gierens \& Ponater 1999). Quantification of the possible mechanisms that could influence (condensation nuclei; ion-induced) cloud formation and thus global climate has only just begun (Gray et al. 2010). Recent results from the CLOUD experiment by Kirkby et al. (2011) suggest that cosmic rays indeed have an effect on the atmosphere, as high-energy protons increase the production of nanometer-sized particles. However, the connection between cloud formation and cosmic rays is far from firmly established, and the effects of increased cloud formation as a forcing factor on climate change are even more uncertain.

\section{Historical and palaeoclimatological evidence for the influence of TSI on Earth's climate}

\subsection{Decadal scale}

Many studies have tried to correlate observations of temperature at the Earth's surface to the 11-year variation in TSI as measured during the last three decades and to deduce causal relationships from that correlation. A problem with such correlations is the fact that many other climate forcing factors (such as aerosol concentrations, greenhouse gasses, volcanic activity) have changed considerably over the last three decades as well. This problem of covariance can be (partly) overcome by studying periods of time that predate human disturbance of the atmosphere.

Systematic sun spot observations began after the invention of the telescope around 1610 AD (Gray et al. 2010). Instrumental measurements of climate parameters such as temperature reach back even further (Luterbacher et al. 2004). Cold winter temperatures were observed in a compilation dataset of monthly-to-seasonal temperature records for the 16th century, the late 17th century and the end of the 19th century (Luterbacher et al. 2004). These time intervals are together often referred to as the Little Ice Age and are characterized by long periods of low solar activity, encompassing the so-called Maunder Minimum (Eddy 1976). Using the same instrumental dataset, Xoplaki et al. (2005) showed that the coldest springs appeared during the Maunder Minimum as well, with the average temperature being $1{ }^{\circ} \mathrm{C}$ lower than over the period 1901-2000 AD. The combined evidence of Luterbacher et al. (2004) and Xoplaki et al. (2005) shows that the widely reported cold temperatures during the Maunder Minimum/Little Ice Age are mainly a winter/early spring phenomenon. Model simulations by Shindell et al. (2003) and Luterbacher et al. (2004) show that an increase in solar irradiance just following the end of the LIA might have induced a shift toward a positive NAO-index during the winter months. Xoplaki et al. (2005) therefore conclude that changes in solar irradiance might be a major trigger in explaining European (spring) temperature at a decadal timescale.

There is also palaeoclimatological evidence for solar forcing of climate on decadal timescales. For instance, Haltia-Hovi et al. (2007) measured varve (annual laminae in lake sediments) thickness in a lacustrine sediment body from eastern Finland and showed that well-known climatic periods of the last millennium (i.e. the Medieval Climate Anomaly and the Little Ice Age) are represented in their records. Another example of palaeoclimatological evidence for solar forcing of recent climate change is presented by Sejrup et al. (2010) who published a high-resolution record of past changes in ocean water temperature. Their 1000-year long sediment record from the Norwegian Sea shows distinct $1-2{ }^{\circ} \mathrm{C}$ decadal- to centennial-scale changes in sea surface temperatures that are strongly correlated to proxies of past solar activity. Additionally, Oldfield et al. (1997) and Mauquoy et al. (2002) found reduced carbon accumulation rates in Swedish and British peat bogs between $\sim 1400$ and $1800 \mathrm{AD}$. The authors attribute this reduced primary productivity to lower spring and summer temperatures. The peat stratigraphy presented by Mauquoy et al. (2002) shows several wet shifts, mainly corresponding to periods with steep increases in $\Delta^{14} \mathrm{C}$ which are most likely a consequence of increased ${ }^{14} \mathrm{C}$ production as a result of low solar activity.

From a climate perspective, changes on decadal timescales are often of only minor importance, as many processes that control the climate system act on longer timescales. However, even short and small-scale changes in the energy balance of the sun might prompt non-linear large responses, such as perturbations of the thermohaline circulation or changes in atmospheric circulation (e.g. Martin-Puertas et al. 2012).

\subsection{Centennial to millennial scale}

Historical sources only encompass a couple of centuries in most areas. Research that focuses on timescales predating this interval therefore needs to rely on indirect evidence of past changes in solar activity as well as past changes in climate. Proxy-data can be retrieved from natural archives such as ice-cores, marine and lacustrine sediment records, speleothems, peat deposits and tree rings. Some of these natural archives of climate change have simultaneously also recorded changes in radionuclide concentrations, which can be used as a proxy for changes in TSI. For example, tree rings have an annual resolution, reflect different parameters of the climate system (for instance, through temperature-dependent tree ring width) and contain a record of the cosmogenic isotope ${ }^{14} \mathrm{C}$ that reflects past solar activity. The first advantage of using proxy-data records lies in the fact that they cover $10^{2}-10^{4}$ years in high resolution (up to annual data). Second, these records allow investigation of the influence of TSI on climate for periods where mankind was not yet actively 
influencing its environment, or where other climate forcing factors such as volcanic activity were passive. It is however also evident that the availability of these proxy-records is not equally distributed over the globe and that the quality of the data differs from site to site.

Many palaeoclimatic records suggest a link between changes in TSI and climate. One of the most prominent examples of a sun-climate relationship is the climate shift that occurred in many parts of the world around 2800 calendar years BP (BP being "before 1950 AD"). The (dendrochronology-based) ${ }^{14} \mathrm{C}$ calibration curve shows a sharp rise in $\Delta^{14} \mathrm{C}$ between 2800 and 2700 cal. year BP, representing a period of increased ${ }^{14} \mathrm{C}$ production and therefore indicating a time interval with low solar activity. Kilian et al. (1995) were able to show that the sharp rise in $\Delta^{14} \mathrm{C}$ starting around 2800 cal. year BP occurred simultaneous with the transition from "Older Sphagnum peat" to "Younger Sphagnum peat" at the Subboreal/Subatlantic transition in northwest European raised bogs (van Geel et al. 1996). van Geel (1978) showed a detailed peat section from the Netherlands, where the author interpreted the change from Older to Younger Sphagnum peat to be the result of a change from relatively warm and dry conditions to more wet and/or cold conditions. Simultaneously, large areas in western and central Netherlands experienced a decrease in population densities, as many locations became uninhabitable as a result of increased precipitation, rising groundwater tables or impeded drainage (van Geel et al. 1996). In a review of other studies that showed evidence of climate change around 2800 cal. year BP, van Geel et al. (1996) list data from Ireland, the UK, Germany and further east to Poland and north to Fennoscandia. Magny (1993) also provides evidence for large-scale climate change around 2800 cal. year BP showing a regional-scale lake-level rise around $2800 \mathrm{cal}$. year BP in southern France and Switzerland.

An additional study by van Geel et al. (2000) shows a record of climate change in Chile around 2700 cal. year BP, where changing atmospheric circulation patterns resulted in precipitation-driven shifts in vegetation belts and glacier advances between 2700 and 2000 cal. year BP (Grosjean et al. 1998; van Geel et al. 2000). In south-central Siberia, an acceleration of cultural development can be seen concurrent with a change to more humid conditions and a shift from semidesert-like environments to steppe landscapes. The newly available steppe areas could be invaded by herbivores, making them attractive for nomadic tribes (van Geel et al. 2004). A reconstructed dryness crisis in central West Africa (Reynaud-Farrera et al. 1996) provides additional evidence for large-scale climate change around $2800 \mathrm{BP}$ and points to a role of UV and ozone in the amplification of changing solar activity (van Geel et al. 2001). The combined evidence points toward a large-scale (maybe even global) reorganization of atmospheric circulation patterns around $2800 \mathrm{cal}$. year BP and a decrease in temperatures in Europe. The concurrent decline of solar activity seems to be the most likely forcing agent that can explain the changes seen in the climate system. The pattern of changes in temperature and precipitation as observed over the globe resembles the pattern of change that van Geel \& Renssen (1998) deduced from model experiments by Haigh $(1994,1996)$. Haigh modelled the effects of an increase in solar activity, the resulting increased UV radiation and stratospheric ozone concentrations and the subsequent change in climate. Using these climate model simulations, she was able to show that an increase in stratospheric ozone content would result in a poleward displacement of the Hadley Cells as well as of the mid-latitude storm tracks. van Geel \& Renssen (1998) argue that a decrease in solar activity would show the opposite results of Haigh's experiment, i.e. a decrease in the latitudinal extent of the Hadley Cell circulation, an equatorward relocation of the mid-latitude storm tracks, cooling in the mid- to high-latitudes and a shift in the main precipitation belts (van Geel \& Renssen 1998; Renssen et al. 2000). This pattern of climate change strongly resembles the recorded palaeoclimatological observations. Furthermore, the combined reconstructions for the period around $2800 \mathrm{cal}$. year BP resemble the results of Luterbacher et al. (2001) who suggest that NW Europe was both wetter and cooler than today during the Maunder Minimum, a period with comparably low solar activity.

Another example is the study by Chen et al. (2011), who reconstructed sea surface temperatures and precipitation (through river discharge) changes using a marine sediment record from the Gulf of Taranto (Italy). The authors show that both temperature and precipitation had a cyclic character with main cyclicities of 7-8 and 11 years. Chen et al. (2011) observe a strong correlation between their reconstructions and global variations in $\Delta^{14} \mathrm{C}$, and argue that solar variability might have been a major forcing mechanism of the regional climate for the period $60 \mathrm{BC}-200 \mathrm{AD}$.

Theoretically, it is unlikely that millennial-scale climate oscillations are directly forced by changes in TSI, the variability of which acts on a decadal to centennial timescale. However, even weak forcing such as TSI might trigger long-term changes in the climate system when (a) present over a long time, (b) non-linear feedback mechanisms amplify the original forcing or (c) when certain thresholds are crossed.

Based on the periodic reoccurrence of ice-rafted debris in sediment cores from the Atlantic ocean, Bond et al. (1997) identified a millennial-scale periodicity of cooling events that were not only present during the previous glacial but that also continued into the Holocene. Bond et al. (1997) proposed that the cooling phases were part of a millennial-scale climatic cycle (ca. 1500 years) that was most likely the result of an intrinsic driver in the atmosphere-ocean system. Later work by Bond et al. (2001) argues that a strong sun-climate link persisted during the Holocene and that changes in solar activity caused the millennial-scale cyclicity as observed in the sediment records.

Magny (2006) compiled evidence for lake-level changes for 26 lakes in France and Switzerland. He showed that there are distinct phases of high or low lake levels that can be identified throughout the region. The periods that are characterized by higher lake levels coincide with periods with more ice-rafting in the Atlantic Ocean as well as with minima in solar activity (as derived from the ${ }^{14} \mathrm{C}$ record). Second, Magny (2004) was able to demonstrate from archaeological evidence that periods of lower lake levels in the Jura mountains (coinciding with phases of solar maxima) occurred simultaneous with the (increased) development of prehistoric lake dwellings. However, Magny (2004) remarks that the development of lake-shore villages did not solely depend on solar activity but that cultural factors impacted the local population as well.

Recent high-resolution foraminiferal-based sea surface temperature reconstructions show that there is a link between Holocene climate fluctuations reconstructed from Northern Hemispheric sediment cores and 1000-year and 2500-year cyclicity of TSI variability (Debret et al. 2009; Marchitto et al. 2010; Cléroux et al. 2012). The covariance between the solar and climate signals is clearly identifiable for the early Holocene (between $\sim 9.5$ and $7 \mathrm{kyr}$ BP). However, the link 
between TSI and climate is less clear for the Middle to Late Holocene. This might be explained by a decreased power of the 1000-year TSI cycle during the Middle to Late Holocene, or by the overriding influence of thermohaline forcing of the climate (Debret et al. 2009).

A high-resolution $\partial^{18} \mathrm{O}$ record from a stalagmite from Oman (interpreted as a proxy for changing rainfall intensity) shows a strong correspondence with the fluctuations of the $\Delta{ }^{14}$ C-record (Neff et al. 2001). The resemblance between the two independent datasets points to solar forcing of climate change and a regional climate system that is sensitive to relatively small changes in solar activity. For an overview of recent publications about solar forcing of climate change, we refer to http://www.chrono.qub.ac.uk/blaauw/cds.html.

\section{Climate model simulations}

The pattern in the response of the climate system to external forcing can be very different from the initial pattern in the forcing itself due to the effects of non-linear feedback mechanisms. This is true for all different types of climate forcing mechanisms, including solar forcing. It is therefore not an easy task to attribute past climate changes to a combination of different forcings, or even to a single forcing mechanism. Climate model simulations provide a means for testing the influence of a single forcing factor on the climate system. It is also possible to simulate climate response to a combination of forcing factors, such as increasing greenhouse gas concentrations and an increase in TSI.

The direct effects of changes in TSI on Earth's energy balance (mainly through the uptake of solar heat by oceans; the "bottom-up mechanism") are often adequately represented in climate models. Model simulations that include most known forcing factors (TSI, greenhouse gasses, volcanic activity, aerosols and ozone) show that for the first half of the 20th century, most of the global warming can be attributed to natural forcing (Stott et al. 2000; Tett et al. 2002; Meehl et al. 2004; Gray et al. 2010). However, temperature changes during the second half of the 20th century are considered to be most likely the result of the increased concentration of greenhouse gasses.

Unfortunately, most climate models do not include a fully resolved stratosphere and cannot model detailed UV effects (e.g. Feulner \& Rahmstorf 2010; Gray et al. 2010). Kodera \& Kuroda (2002) do model the increased UV radiation during a solar maximum and show that this feedback mechanism reinforces the direct effects of changes in TSI. Recent model simulations by Ineson et al. (2011) also confirm a "top-down" pathway for high-latitudinal response to solar variability. Their model simulations show that phases characterized by low solar activity result in a pressure and temperature pattern at the Earth's surface that resembles the negative phase of the NAO index.

Several climate models indicate that the pattern of climate response at the Earth's surface to changes in TSI is similar to the response to changes in greenhouse gasses (Gray et al. 2010 and references therein). The climate response is amplified at the high latitudes, where albedo effects form a positive feedback mechanism. The similar pattern of response implies that although there is a correlation between surface air temperatures and solar activity data (Thejll \& Lassen 2000), this is no proof that there is a causal relationship between the two parameters. Gray et al. (2010) suggest that the correlation between surface temperatures and solar activity for the 20th century is more likely the result of a coincidental similarity in sunspot activity and hemispheric mean temperatures, where the temperature increase is more likely to be attributed to increasing greenhouse gasses.

Climate model simulations that include a representation of both TSI-climate feedback mechanisms and that combine a resolved stratosphere as well as a dynamic ocean are few. However, these models will be vital in identifying the sensitivity of ocean circulation to solar forcing and in determining the possible feedback that can result from changes in the oceanic circulation.

\section{Concluding remarks}

The role of solar variability as a forcing mechanism of past, present and future climate change still raises many questions. Changes in solar activity between maxima and minima of the 11-year solar cycle during the last three solar cycles only amount to a change of $\sim 0.07 \mathrm{~W} \mathrm{~m}^{-2}$ in direct radiative forcing at the Earth's surface, which is small compared to the estimated effect of a doubling of atmospheric $\mathrm{CO}_{2}$ concentrations $\left(\sim 3.7 \mathrm{~W} \mathrm{~m}^{-2}\right)$. Several feedback mechanisms have been proposed to explain how the small-scale changes in TSI can have an effect on climate, including an increase in stratospheric ozone concentrations as a result of increased UV-radiation during a solar maximum.

Palaeoclimatic reconstructions based on material from natural archives such as lake and ocean sediments, peat deposits, tree rings and ice cores are becoming increasingly more detailed, both in terms of their resolution (e.g. annual data) and in terms of providing quantitative evidence of past climatic changes. Historical and palaeoclimatological records indicate that past changes in Earth's climate system occurred simultaneously with changes in solar activity, suggesting that the climate system is sensitive to even small changes in solar activity. This paper reviews climate changes on a decadal timescale (e.g. the Little Ice Age) as well as on a centennial to millennial timescale (e.g. the climate shift around 2800 cal. year BP) that can (partly) be attributed to changes in solar variability. However, we are still far away from a complete understanding of all the physical processes and feedback mechanisms that are involved in potential solar forcing of climate change.

Quantification of past changes in the climate system through high-resolution data analysis will enable us to determine both pattern and timing of climate change in the past, which will ultimately lead to a determination of processes that drove these past changes. Simultaneous, developments in the field of climate modelling are rapid and will allow testing of different hypotheses on sun-climate relationships. Ultimately, a better understanding of the effects of changes in TSI on the Earth's climate will help us to limit the uncertainty in the importance of human activity as a forcing factor for the current changes in global climate.

The 20th-century Grand Maximum of solar activity probably has come to an end (e.g. Clilverd et al. 2006; de Jager \& Duhau 2009; Lockwood et al. 2009) and relatively low solar activity is predicted for the next few decades. Model simulations by Feulner \& Rahmstorf (2010) suggest that the effects of a new Grand Minimum of solar activity will lead to a decrease in global mean temperatures of only $0.1{ }^{\circ} \mathrm{C}$ (or possibly $0.3{ }^{\circ} \mathrm{C}$, taking all model uncertainties into account). This is a comparatively minor number compared to the $3.7-4.5{ }^{\circ} \mathrm{C}$ temperature increase that is expected to result from the 
increased emission of greenhouse gasses (Feulner \& Rahmstorf 2010). Similar results are obtained by Jones et al. (2012), who predict a decrease in warming of $0.06-0.1{ }^{\circ} \mathrm{C}$ as a result of decreased solar activity in the 21 st century. Recent results by Solheim et al. (2012) illustrate that solar cycle length is correlated to temperatures around the North Atlantic region during the next solar cycle. This suggests that Atlantic currents play a role as a reinforcement agent of the solar signal and that an Arctic cooling might be expected during solar cycle 24 (Solheim et al. 2012).

Acknowledgements. We thank the organizing committee for inviting us to contribute this review paper to the proceedings of the Space Climate 4 Symposium in Goa (January 2011). BvG thanks the organizers of the symposium for the invitation to give a keynote lecture about palaeo-evidence for solar forcing of climate change. We are grateful for the helpful comments of two anonymous reviewers.

\section{References}

Baldwin, M.P., and T.J. Dunkerton, Propagation of the Arctic oscillation from the stratosphere to the troposphere, J. Geophys. Res., 104, 30937-30946, 1999.

Beer, J., and B. van Geel, Holocene Climate Change and the Evidence for Solar and other Forcings. In Natural Climate Variability and Global Warming: A Holocene Perspective, ed. R.W., Battarbee, and H.A. Binney, Oxford, UK, Wiley Blackwell, 2008.

Berger, A., Milankovitch theory and climate, Rev. Geophys., 26, 624-657, 1988.

Bond, G., W. Showers, M. Cheseby, R. Lotti, P. Almasi, P. deMenocal, P. Priore, H. Cullen, I. Hajdas, and G. Bonani, A pervasive millennial-scale cycle in North Atlantic Holocene and glacial climates, Science, 278, 1257-1266, 1997.

Bond, G., B. Kromer, J. Beer, R. Muscheler, M.N. Evans, W. Showers, S. Hoffmann, R. Lotti-Bond, I. Hajdas, and G. Bonani, Persistent solar influence on North Atlantic climate during the Holocene, Science, 294, 2130-2136, 2001.

Broecker, W.S., Was the medieval warm period global? Science, 291, 1497-1499, 2001.

Chen, L., K.A.F. Zonneveld, and G.J.M. Versteegh, Short term climate variability during "Roman Classic Period" in the eastern Mediterranean, Quat. Sci. Rev., 30, 3880-3891, 2011.

Cléroux, C., M. Debret, E. Cortijo, J.-C. Duplessy, F. Dewilde, J. Reijmer, and N. Massei, High-resolution sea surface reconstructions off Cape Hatteras over the last $10 \mathrm{ka}$, Paleoceanography, 27, PA1205, 2012.

Clilverd, M.A., E. Clarke, T. Ulich, H. Rishbeth, and M.J. Jarvis, Predicting solar cycle 24 and beyond, Space Weather, 4, S09005, 2006.

Cubasch, U., R. Voss, G.C. Hegerl, J. Waszkewitz, and T.C. Crowley, Simulation with an O-AGCM of the influence of variations of the solar constant on the global climate, Clim. Dyn., 13, 757-767, 1997.

Cubasch, U., E. Zorita, F. Kaspar, J.F. Gonzales-Rouco, H. von Storch, and K. Prommel, Simulation of the role of solar and orbital forcing on climate, Adv. Space Res., 37, 1629-1634, 2006.

de Jager, C., and S. Duhau, Forecasting the parameters of sunspot cycle 24 and beyond, J. Atm. Solar-Terr. Phys., 71, 239-245, 2009.

Debret, M., D. Sebag, X. Crosta, N. Massei, J.-R. Petit, E. Chapron, and V. Bout-Roumazeilles, Evidence from wavelet analysis for a mid-Holocene transition in global climate forcing, Quat. Sci. Rev., 28, 2675-2688, 2009.

Diffenbaugh, N.S., and L.C. Sloan, Global climate sensitivity to land surface change: the mid Holocene revisited, Geophys. Res. Lett., 29 (10), 1476, DOI: 10.1029/2002GL014880, 2002.
Eddy, J.A., The Maunder Minimum, Science, 192, 1189-1202, 1976.

Feulner, G., and S. Rahmstorf, On the effect of a new grand minimum of solar activity on the future climate of Earth, Geophys. Res. Lett., 37, L05707, 2010.

Frame, T.H.A., and L.J. Gray, The 11-year solar cycle in ERA-40 data: an update to 2008, J. Clim., 23, 2213-2222, 2010.

Fröhlich, C., Solar irradiance variability since 1978: revision of the PMOD composite during solar cycle 21, Space Sci. Rev., 125, 5365, 2006.

Fröhlich, C., Observational evidence of a long-term trend in total solar irradiance, Astronom. Astrophys., 501, L27-L30, 2009.

Gierens, K., and M. Ponater, Comment on "Variation of cosmic ray flux and global cloud coverage - a missing link in solar-climate relationships" by H. Svensmark and E. Friis-Christensen, J. Atm. Solar-Terr. Phys., 61, 795-797, 1999.

Graf, H.-F., I. Kirchner, A. Robock, and I. Schult, Pinatubo eruption winter climate effects: Model versus observations, Clim. Dyn., 9, 81-93, 1993.

Gray, L.J., S.T. Rumbold, and K.P. Shine, Stratospheric temperature and radiative forcing response to 11-year solar cycle changes in irradiance and ozone, J. Atm. Sci., 66, 2402-2417, 2009.

Gray, L.J., J. Beer, M. Geller, J.D. Haigh, M. Lockwood, et al., Solar influences on climate, Rev. Geophys., 48, 1-53, 2010.

Grosjean, M., M.A. Geyh, B. Messerli, H. Schreier, and H. Veit, A late-Holocene $(<2600 \mathrm{BP})$ glacial advance in the southcentral Andes $\left(29^{\circ} \mathrm{S}\right)$, northern Chile, Holocene, 8, 473-479, 1998.

Haigh, J.D., The role of stratospheric ozone in modulating the solar radiative forcing of climate, Nature, 370, 544-546, 1994.

Haigh, J.D., The impact of solar variability on climate, Science, 272, 981-984, 1996

Haltia-Hovi, E., T. Saarinen, and M. Kukkonen, A 2000-year record of solar forcing on varved lake sediment in eastern Finland, Quat. Sci. Rev., 26, 678-689, 2007.

Herschel, W., Observations tending to investigate the nature of the Sun, in order to find the causes or symptoms of its variable emission of light and heat: With remarks on the use that may possibly be drawn from solar observations, Philos. Trans. R. Soc. London, 91, 265-318, 1801.

Hurrell, J.W., and H. van Loon, Decadal variations in climate associated with the North Atlantic Oscillation, Clim. Change, 36, 301-326, 1997.

Indermühle, A., T.F. Stocker, F. Joos, H. Fischer, H.J. Smith, et al., Holocene carbon-cycle dynamics based on $\mathrm{CO}_{2}$ trapped in ice at Taylor Dome, Antarctica, Nature, 398, 121-126, 1999.

Ineson, S., A.A. Scaife, J.R. Knight, J.C. Manners, N.J. Dunstone, L.J. Gray, and J.D. Haigh, Solar forcing of winter climate variability in the Northern Hemisphere, Nature Geosci., 4, 753757, 2011.

IPCC, Climate change 2007: The physical science basis, Contribution of Working Group I to the Fourth Assessment Report of the IPCC, ISBN 9780521 88009-1, 2007.

Johnsen, S.J., H.B. Clausen, W. Dansgaard, K. Fuhrer, N. Gundestrup, C.U. Hammer, P. Iversen, J. Jouzel, B. Stauffer, and J.P. Steffensen, Irregular glacial interstadials recorded in a new Greenland ice core, Nature, 359, 311-313, 1992.

Jones, G.S., M. Lockwood, and P.A. Stott, What influence will future solar activity changes over the 21 st century have on projected global near-surface temperature change? J. Geophys. Res., 117, D05103, 2012.

Joos, F., and R. Spahni, Rates of change in natural and anthropogenic radiative forcing over the past 20,000 years, Proc. Nat. Acad. Sci., 105, 1425-1430, 2008.

Jørgensen, T.S., and A.W. Hansen, Comments on "Variation of cosmic ray flux and global cloud coverage - a missing link in solar-climate relationships" by Henrik Svensmark and Eigil FriisChristensen, J. Atm. Solar-Terr. Phys., 62, 73-77, 2000. 
Kilian, M.R., J. van der Plicht, and B. van Geel, Dating raised bogs: New aspects of AMS ${ }^{14} \mathrm{C}$ wiggle matsching, a reservoir effect and climatic change, Quat. Sci. Rev., 14, 959-966, 1995.

Kirkby, J., J. Curtius, J. Almeida, E. Dunne, J. Duplissy, et al., Role of sulphuric acid, ammonia and galactic cosmic rays in atmospheric aerosol nucleation, Nature, 476, 429-433, 2011.

Kodera, K., and Y. Kuroda, Dynamical response to the solar cycle: winter stratopause and lower stratosphere, Geophys. Res. Lett., 33, 2002.

Kushner, P.J., and L.M. Polvani, Stratosphere-troposphere coupling in a relatively simple AGCM: the role of eddies, J. Clim., 17, 629-639, 2004.

Lockwood, M., Solar influence on global and regional climates, Surv. Geophys., 3-4, 503-534, 2012.

Lockwood, M., A.P. Rouillard, and I.D. Finch, The rise and fall of open solar flux during the current grand solar maximum, $J$. Astrophys., 700, 937-944, 2009.

Lockwood, M., C. Bell, T. Woollings, R.G. Harrison, L.J. Gray, and J.D. Haigh, Top-down solar modulation of climate: evidence for centennial-scale change, Environ. Res. Lett., 5, 034008, 2010.

Luterbacher, J., R. Rickli, E. Xoplaki, C. Tinguely, C. Beck, C. Pfister, and H. Wanner, The late Maunder Minimum (1675-1715) - a key period for studying decadal scale climatic change in Europe, Clim. Change, 49, 441-462, 2001.

Luterbacher, J., D. Dietrich, E. Xoplaki, M. Grosjean, and H. Wanner, European seasonal and annual temperature variability, trends and extremes since 1500, Science, 303, 1499-1503, 2004

Magny, M., Solar influences on Holocene climatic changes illustrated by correlations between past lake-level fluctuations and the atmospheric ${ }^{14} \mathrm{C}$ record, Quat. Res., 40, 1-9, 1993.

Magny, M., Holocene climate variability as reflected by midEuropean lake-level fluctuations and its probable impact on prehistoric human settlements, Quat. Int., 113, 65-79, 2004.

Magny, M., Holocene fluctuations of lake levels in west-central Europe: Methods of reconstruction, regional pattern, palaeoclimatic significance and forcing factors, Encycl. Quat. Geol., 2, 1389-1399, 2006.

Marchitto, T.M., R. Muscheler, J.D. Ortiz, J.D. Carriquiry, and A. van Geen, Dynamical response of the tropical Pacific Ocean to solar forcing during the Early Holocene, Science, 330, 1378$1381,2010$.

Martin-Puertas, C., K. Matthes, A. Brauer, R. Muscheler, F. Hansen, C. Petrick, A. Aldahan, G. Possnert, and B. van Geel, Regional atmospheric circulation shifts induced by a grand solar minimum, Nature Geosci., 5, 397-401, 2012.

Matthes, K., Y. Kuroda, K. Kodera, and U. Langematz, Transfer of the solar signal from the stratosphere to the troposphere: northern winter, J. Geophys. Res., 111, D06108, 2006.

Mauquoy, D., T. Engelkes, M.H.M. Groot, F. Markesteijn, M.G. Oudejans, J. van der Plicht, and B. van Geel, High-resolution records of late-Holocene climate change and carbon accumulation in two north-west European ombrotrophic peat bogs, Palaeogeog., Palaeoclimatol., Palaeoecol., 186, 275-310, 2002.

McHargue, L.R., and P.E. Damon, The global Beryllium 10 cycle, Rev. Geophys., 29, 141-158, 1991.

Meehl, G.A., W.M. Washington, C.M. Amman, J.M. Arblaster, T.M.L. Wigley, and C. Tebaldi, Combinations of natural and anthropogenic forcings and 20th century climate, J. Clim., 17, 3721-3727, 2004

Meehl, G.A., J.M. Arblaster, G. Branstator, and H. van Loon, A coupled air-sea response mechanism to solar forcing in the Pacific region, J. Clim., 21, 2883-2897, 2008.

Meehl, G.A., J.M. Arblaster, K. Matthes, F. Sassi, and H. van Loon, Amplifying the Pacific climate system response to a small 11 year solar cycle forcing, Science, 325, 1114-1118, 2009.

Milankovitch, M., Kanon der Erdbestrahlung und seine Anwendung auf das Eiszeitenproblem [Canon of insolation of the Earth and its application to the problem of the Ice Ages], Royal Serb. Sci. Spec. Publ., 132, 626, 1941.

Neff, U., S.J. Burns, A. Mangini, M. Mudelsee, D. Fleitmann, and A. Matter, Strong coherence between solar variability and the monsoon in Oman between 9 and 6 kyr ago, Nature, 411, 290 293, 2001.

Oldfield, F., R. Thompson, P.R.J. Crooks, S.J. Gedye, V.A. Hall, et al., Radiocarbon dating of a recent high-latitude peat profile: Stor Åmyrân, northern Sweden, Holocene, 7, 283-290, 1997.

Reimer, P.J., M.G.L. Baillie, E. Bard, A. Bayliss, J.W. Beck, et al., IntCal04 terrestrial radiocarbon age calibration, $0-26$ cal kyr BP, Radiocarbon, 51, 1111-1150, 2009.

Renssen, H., B. van Geel, J. van der Plicht, and M. Magny, Reduced solar activity as a trigger for the start of the Younger Dryas? Quat. Int., 68-71, 373-383, 2000.

Renssen, H., H. Seppä, O. Heiri, D.M. Roche, H. Goosse, and T. Fichefet, The spatial and temporal complexity of the Holocene thermal maximum, Nature Geosci., 2, 411-414, 2009.

Reynaud-Farrera, I., J. Maley, and D. Wirrman, Végétation et climat dans les fôrets du Sud-Ouest Cameroun depuis 4470 ans BP: analyse pollinique des sediments du Lac Ossa [Vegetation and climate in the forests of southwest Cameroon since 4470 years BP: pollen-analysis on the sediments of Lake Ossa], C. R. Acad. Sci., 322, 749-755, 1996.

Robock, A., Volcanic eruptions and climate, Rev. Geophys., 38, 191219, 2000.

Ruddiman, W.F., The anthropogenic greenhouse era began thousands of years ago, Clim. Change, 61, 261-293, 2003.

Sejrup, H.P., S.J. Lehman, H. Haflidason, D. Noone, R. Muscheler, I.M. Berstad, and J.T. Andrews, Response of Norwegian Sea temperature to solar forcing since 1000 A.D., J. Geophys. Res., 115, C12034, 2010

Shindell, D., G. Schmidt, R. Miller, and M. Mann, Volcanic and solar forcing of climate change during the preindustrial era, J. Clim., 16, 4094-4107, 2003.

Simpson, I.R., M. Blackburn, and J.D. Haigh, The role of eddies in driving the tropospheric response to stratospheric heating perturbations, J. Atmos. Sci., 66, 1347-1365, 2009.

Solheim, J.-E., K. Stordahl, and O. Humlum, The long sunspot cycle 23 predicts a significant temperature decrease in cycle $24, \mathrm{~J}$. Atm. Solar-Terr. Phys., 80, 267-284, 2012.

Steinhilber, F., J. Beer, and C. Fröhlich, Total solar irradiance during the Holocene, Geophys. Res. Lett., 36, L19704, 2009.

Stott, P.A., S.F.B. Tett, G.S. Jones, M.R. Allen, J.F.B. Mitchell, and G.J. Jenkins, External control of 20th century temperature variations by natural and anthropogenic forcings, Science, $\mathbf{2 0 9}$, 2133-2137, 2000.

Stuiver, M., and J. van der Plicht, INTCAL 98: calibration issue, Radiocarbon, 40, 1041-1159, 1998.

Stuiver, M., P.J. Reimer, E. Bard, J.W. Beck, G.S. Burr, K.A. Hughen, B. Kromer, J. van der Plicht, and M. Spurk, INTCAL98 radiocarbon age calibration, 24,000-0 cal BP, Radiocarbon, 40, 1041-1083, 1998.

Svensmark, H., and E. Friis-Christensen, Variation of cosmic ray flux and global cloud coverage - a missing link in solar-climate relationships, J. Atm. Solar-Terr. Phys., 59, 1225-1232, 1997.

Svensmark, H., T. Bondo, and J. Svensmark, Cosmic ray decreases affect atmospheric aerosols and clouds, Geophys. Res. Lett., 36, L15101, 2009.

Tett, S.F.B., G.S. Jones, P.A. Stott, D.C. Hill, F.J.B. Mitchell, et al., Estimation of natural and anthropogenic contributions to twentieth century temperature change, J. Geophys. Res., 107, 2002.

Thejll, P., and K. Lassen, Solar forcing of the Northern Hemisphere land air temperature: new data, J. Atm. Solar-Terr. Phys., 62, 1207-1213, 2000.

van Geel, B., A palaeoecological study of Holocene peat bog sections in Germany and the Netherlands, Rev. Palaeobot. Palynol., 25, 1-120, 1978. 
S. Engels and B. van Geel: Solar activity and climate of the past

van Geel, B., and H. Renssen, Abrupt climate change around 2650 BP in North-West Europe: evidence for climatic teleconnections and a tentative explanation, In Water, Environment and Society in Times of Climate Change, ed. A., Issar, and N. Brown, Dordrecht, Kluwer, 21-41, 1998.

van Geel, B., J. Buurman, and H.T. Waterbolk, Archeological and palaeoecological indications of an abrupt climate change in The Netherlands, and evidence for climatological teleconnections around 2650 BP, J. Quat. Sci., 11, 451-460, 1996.

van Geel, B., C.J. Heusser, H. Renssen, and C.J.E. Schuurmans, Climatic change in Chile at around $2700 \mathrm{BP}$ and global evidence for solar forcing: a hypothesis, Holocene, 10, 659-664, 2000.

van Geel, B., H. Renssen, and J. van der Plicht, Evidence from the past: solar forcing of climate change by way of cosmic rays and/or by solar UV? In Proceedings Workshop on Ion-Aerosol-Cloud Interactions, ed. J., Kirkby, Geneva, CERN, 24-29, 2001. van Geel, B., N.A. Bokovenko, N.D. Burova, K.V. Chugunov, V.A. Dergachev, et al., Climate change and the expansion of the Scythian culture after 850 BC: a hypothesis, J. Archaeol. Sci., 31, 1735-1742, 2004.

Vandenberghe, J., G.R. Coope, and C. Kasse, Quantitative reconstructions of palaeoclimates during the last interglacial-glacial in western and central Europe: an introduction, J. Quat. Sci., 13, 361-366, 1998

Wanner, H., J. Beer, J. Bütikofer, T.J. Crowley, E. Cubasch, and et al., Mid- to late Holocene climate change: an overview, Quat. Sci. Rev., 27, 1791-1828, 2008.

Xoplaki, E., E.J. Luterbacher, H. Paeth, D. Dietrich, N. Steiner, M. Grosjean, and H. Wanner, European spring and autumn temperature variability and change of extremes over the last half millennium, Geophys. Res. Lett., 32, 2005. 